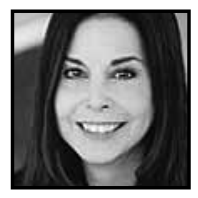

\title{
Educational Uses of the Digital World for Human Development
}

Colette Daiute, The Graduate Center, City University of New York

\section{ABSTRACT}

This article discusses several enduring features of the digital world in relation to the dramatically changing global context and visibility of the human condition. Based on the author's experience as an educator and researcher, she explains that interactivity, multi-modality, and information storage are ripe for advancing students' creative and critical interactions with diverse others and themselves. With the digital world as a focal point, although by no means the only communication medium, educators are in unique positions to guide contemporary human development, which is increasingly an interdependent individual-societal process, thereby requiring knowledge of realities beyond one's own.

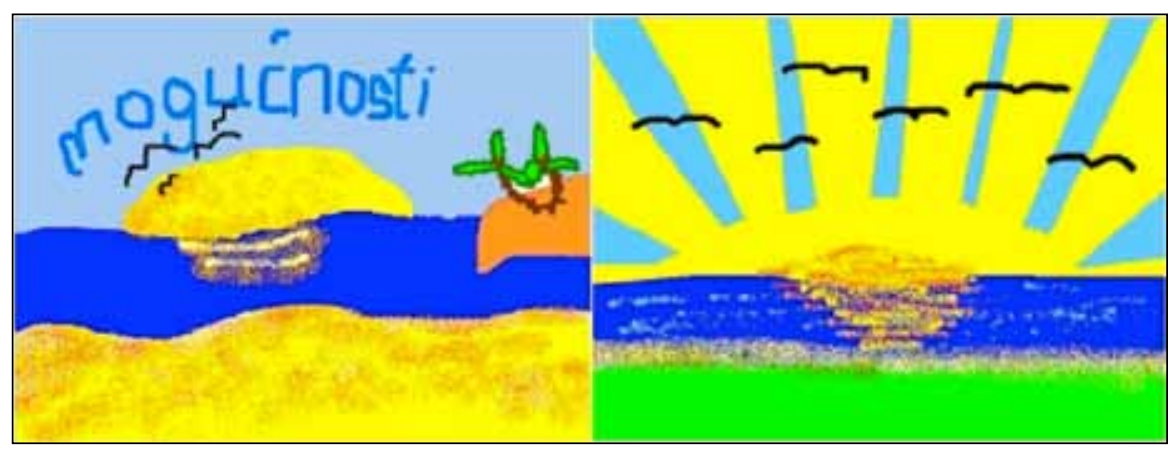

"Future prospects" - Are they on the horizon? 


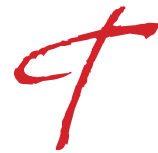

his image of two horizons expresses an ongoing dilemma for teaching and learning in the digital world: Are prospects for teaching and learning in the digital world rising or setting? Does the seemingly limitless access to information and other peoples, at least by those in some parts of the world, increase or decrease educators' roles? What is the best use of precious education time when pre-school through college aged students spend so much of their time in digital worlds: texting, playing multi-user games, using wikis, blogs, or YouTube for term paper resources, learning foreign languages on computer-based programs or apps, and augmenting skills with word-processing and related tools? Guiding students to find meaningful purposes, interactions, and follow-up is more important than ever. How might educators think about the digital world to guide the development of horizons?

In this article, I focus on the capacities of the digital world in relation to challenges and possibilities for individuals and societies in the contemporary global context. Based on my experience as an educator and researcher, I explain that specific capacities of the digital world are ripe for advancing students' creative and critical interactions with diverse others and themselves. With the digital world as a focal point, although by no means the only communication medium, educators can address contemporary human development needs, which are increasingly interdependent, thereby requiring knowledge of realities beyond one's own.

The above image "Mogucnosti"-meaning "Prospects" in Croatian-was created in a research workshop for young people using myriad digital and nondigital tools to support mutual understandings among a generation growing up in countries separated by violent wars during their childhood. The activity culminating in the "Prospects" image was for the 12 to 27 year-old participants to use a digital survey template to create their own online interview with peers in the formerly adversarial countries. The text accompanying the "prospects" image read:

YOUTH OF THE WORLD, WE ARE ASKING YOU TO FILL OUT OUR SURVEY AND ALLOW US TO FIND OUT WHAT YOU WOULD LIKE TO CHANGE IN YOUR COMMUNITY. WHAT ARE THE POSSIBILITIES FOR CHANGE, AND DOES YOUR COMMUNITY HELP YOU IN ACHIEVING THOSE GOALS?

(Daiute, 2010, p. 148)

The digital work young people did in community education centers across the former Yugoslavia was purposeful, relational, and sensitive to each local situation. One hundred thirty seven youth in Bosnia and Herzegovina, Croatia, Serbia, and 
the United States participated in several activities to create local newsletter entries about problems and possibilities in daily life from the youth perspective. These young people created, implemented, responded to, and interpreted the "By and For Youth" survey, as well as writing letters to public officials, narrating personal experiences of conflict, reflecting on adults' interactions in public, reading narratives by peers across the region, and interpreting recent news stories about tensions in their locale. The activities were designed for implementation in the digital world, but not all the centers had such resources, so accommodations for offline participation worked of necessity and well.

Regardless of the specific tools available for creating, exchanging, and responding to the survey, these youth whose lives had been defined by war explained that sharing experiences and opinions with diverse others was a highlight. This comment by one teenager was typical: "I feel powerful thinking about others' responses to a survey I completed a little while ago" (p. 169). While participating in such a global imaginary - thinking about geographically and culturally distant others-the participants' hypothetical thinking, such as considering future education or employment, flourished in conversation with peers, community members, and educators. Activities that involved reviewing the responses of other youth to the same survey one had just completed, as noted by the teen cited above, and to surveys one had created, engage young people's reflection and agency.

Lest an example of a youth workshop with digital and non-digital tools seem limited to one region struggling to overcome war, consider the fact that the digital world makes conflicts, inequalities, and abuses worldwide visible to all with access not only to personal computers but also to public digital displays, news, and conversation. In addition, with the current extensive migration across the globe, people who do not have access to digital technologies are likely to have access to other people on the move. At the time of this writing, for example, millions of children are growing up in societies affected by armed conflict, resulting in unstable living situations, and displacement, often with no access to schooling (www.unhcr.org). As refugees flee to safer ground, they interact with residents, aid workers, and, most prominently, media like radio, newspapers, and billboards, all the while sharing experiences. These technologically enhanced mobilities create what many refer to as a shrinking world.

Diverse global human conditions are exposed in the digital world. Educators can seize the opportunity to use the web to expand students' interactions with situations beyond their own. There is, for example, no excuse for not knowing the 
story of a child living in a refugee camp in Syria or a martyred Egyptian idealist in the stalled "Arab Spring" that sparked the overthrow of dictators in several countries in 2011. Knowing that those situations occurred and why no one is exempt from them have become educational basics.

\section{Global Potential, Questionable Use}

Children and youth in many countries are passing increasing amounts of time in digital worlds, yet evidence is scant that this time is expanding knowledge or communication skills. Digital worlds create the potential for interactions from the most remote places and by the youngest people to major urban centers and the most powerful leaders. The reach of email, social media, wikis, computer-assisted language learning, simulated science environments, tweets, and other digital communication tools via web 2.0 and cell technologies has tremendous potential for teaching and learning about the world from within its chatter. For educators and students of literacy and the human sciences, applications of digital technologies remain potentially useful, albeit not yet fully realized. (Applications in the physical sciences and arts are, of course, also extensive and addressed elsewhere.) Education can make a priority to use digital worlds to close gaps in human relations and human development, if not materially then symbolically with activities that expand students' understandings. The "By and For Youth" survey is but one example of such an application.

Given the presence of others visually, aurally, and textually on screens in our homes, schools, libraries, phones in our hands, and public displays, the educational challenge is to learn how to read, interpret, respond to, and develop with others, especially those who might be difficult to understand. For their own personal, societal, and global benefits, American school children and youth, in particular, stand to benefit from becoming individuals who can communicate, identify problems, and imagine with diverse others. Research has begun to show, for example, that U.S. born youth exhibit less ability to narrate breaches in social interaction from the perspectives of those who differ in origin and experience (Lucić, 2012). Immigrant youth who have experience with people whose histories, language, and knowledge differ from their own, demonstrated an ability to explain others' approaches to solving a problem, while the U.S. born youth offered the same explanation for everyone (Lucić, 2012). Students in a country with the most access to the digital world could be especially good at imagining, empathizing, and interacting with diverse others. Therefore, a challenge for teaching and learning in the digital world is to develop 
and employ symbolic capacities for mutual awareness across divides of national borders, inequalities, stabilities, and geographies. Students who may understandably be drawn to friends' Facebook pages benefit from teachers' guidance in semi-structured activities toward interaction with diverse others, beyond their own standpoints, ideally with understanding and compassion. Building on the view that it's desirable to have many "friends" and "likes," educators can employ features of the digital world to help students consider those who "friend" and "like" something different. The goal is not to agree but to be able to know and to discuss.

\section{Features of Digital Worlds}

Three enduring processes of digital worlds are interactivity, symbolic flexibility, and vast sources of information. These capacities are especially ripe for expanding imagination, knowledge, thought, and action.

\section{Interactivity}

Interactivity of myriad kinds defines the digital world. Direct interaction in the digital world can augment face-to-face interaction. Asking questions and receiving feedback is immediate and fast, for creating seamlessly merged narratives, reports, emails, blogs postings, or social media connections. When tools are not uniformly available, hybrid forms of interactivity can work, as long as there is interactive purpose.

The digital world for the "Dynamic Storytelling by Youth" workshop was, for example, defined as a space for meeting up with others who before the war might have been neighbors, fellow vacationers at the seaside or lake, passers-by, or sweethearts, when, almost a decade after the war, cross-national contact remained problematic if not dangerous. Although these young people living in rural and urban contexts did not all have access to the latest technologies, they did the same activities, supported by several goals of teaching and learning that integrated human and technological capacities and needs. Some community centers had computers donated by international aid organizations, and others welcomed even low-cost tools like markers, pens, and recycled paper. Thus, for some participants in this practice-based study, interaction occurred via the web and instantaneously; for others interaction occurred via borrowed email addresses or post, which took weeks. ${ }^{1}$ 
Participants across the hybrid digital and face-to-face workshops used available tools to reflect on conflicts in their everyday lives, from the perspectives of others, and their own desires for the future. They used word-processing software collaboratively and individually, digital survey tools resident on computers and connected to others on the web, digital drawing tools, printers, publishing software, and peace games. In the absence of digital tools, the young people participated with printed copies of the surveys, shared via borrowed email accounts. Kinds of interaction included face-to-face small group work to generate survey questions, to discuss how participants imagined those who might take their survey, to enter the survey items in an interactive survey tool, and to examine results of a brief test.

Working in self-selected groups of four or five, participants across six international workshops wrote surveys to discover what peers in the other contexts felt about their positions in their newly formed countries. Instructions suggested that participants write a draft survey on paper, following guidelines to "Create a Title for the Survey," "Write questions," and "Decide on a format for each question" (reminding them of formats such as multiple-choice, Likert scales, and open-ended questions-responses in the survey they had completed at the beginning of the workshop). After writing a draft on paper, participants entered it into the online survey-maker application program if computers and the Internet were available, and if not, they handwrote or dictated to a volunteer scribe. To interest potential respondents, the groups designed ads for their surveys, like the one at the beginning of this article.

After entering their ad and questions in the digital survey tool, participants responded to a test version and then made any changes they deemed necessary. The research team compiled the surveys, maintaining every question and merging similar questions. This compiled "By and For Youth" survey resulted in 148 questions in 15 categories, including "Basic Facts; Cultural Life and Media; Society/The Company You Keep; Substance Use and Abuse; Education (including subsections on Relationships with Professors, Skipping School and Favorite Subject, Abuse); Health; Politics; Work; Social Relations and Life in Your Town; Violence and Causes of Violence; Philosophy of Life and Religion; Migration-Moving Across the World; Approaching Marriage. 


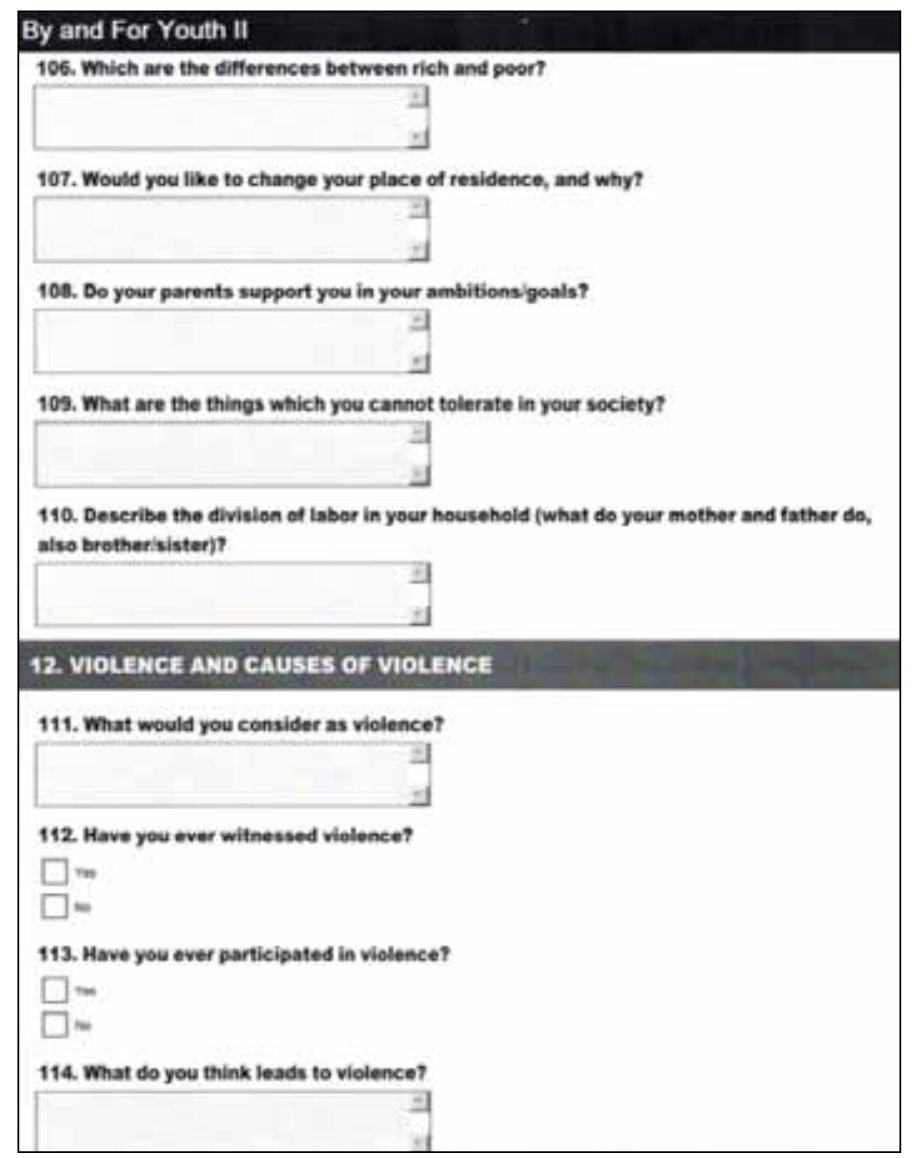

Fig. 1: Youth-designed survey example

Interestingly, issues that emerged in the survey, like war, violence, abuse by professors, homosexuality, and prostitution, remained silent in other genres, suggesting the specific value of the interactive survey for addressing certain complex and controversial issues. Participants wanted to know how the children of their parents' and teachers' adversaries thought, felt, feared, and dreamed about life in the aftermath of war and thereby used the activity - in and out of the digital world - to begin a conversation otherwise silenced. When entering the hypothetical space with their intended survey audiences across borders, participants realized that they did not know about their peers' experiences, nor their news or worries about emigration, for example. After asking about possible emigration to peers who left during the war (many forcibly), survey writers inquired, for example, with questions like, "What's it 
like?" leading to a list of questions that become increasingly skeptical, such as, "Is it really worth leaving your home, family, loved one?" even if you're destined to remain poor? Such a questioning process itself prompted and expanded reflection, even before getting responses.

In summary, in the process of creating surveys that would actually go through the web to different sites, with responses compiled digitally, a goal emerged to learn about the "other side." Such new horizons could eventually continue with ongoing educational support.

\section{Symbolic Flexibility}

Multi-modality -images (moving and still), words, and sounds available for flexible use-is another important feature of the digital world. As stated by researchers, "multimodality can afford, not just a new way to make meaning, but a different kind of meaning" (Hull \& Nelson, 2005, p. 225).

Research with verbal and non-verbal media shows how diverse tools may complement one another to "create new synergies" (Hull \& Nelson, 2005). Hull and Nelson (2005) studied the use of digital storytelling by college students and community groups, illustrating

how (a) the visual pictorial mode can repurpose the written, linguistic mode; (b) iconic and indexical images can be rendered as symbols; (c) titles, iconic, and indexical images and thematic movement can animate each other cooperatively; and (d) modes can progressively become imbued with the associative meanings of each other. (p. 239)

A classroom-based example of multi-media composing drew on capacities of multi-modality (and interactivity) to support writing development of 4 th and 5 th grade students with learning disabilities (Daiute, 1992; Daiute \& Morse, 1993). The research-practice intervention guided students to write a book about their communities via the use of a multi-media composing environment. Students used disposable cameras and cassette audio recorders to collect images and sounds of places, people, or objects they thought depicted the culture of their neighborhoods. Together in the classroom, the students digitized their photos and sounds into a collective database, discussing each one and creating a basic organization of a cultural database. This database included images as diverse as photos of storefronts, $t$-shirts, clips of favorite music, photos of friends, and bedroom walls. The activity was then for students to 
write individual entries for a neighborhood culture book, drawing on multi-media resources as they wished. In addition to the image and sound database, which all students had access to, resources included digital drawing tools, word processing, and basic formatting for arranging words, images, and a sound icon digital printable pages, like the one below.

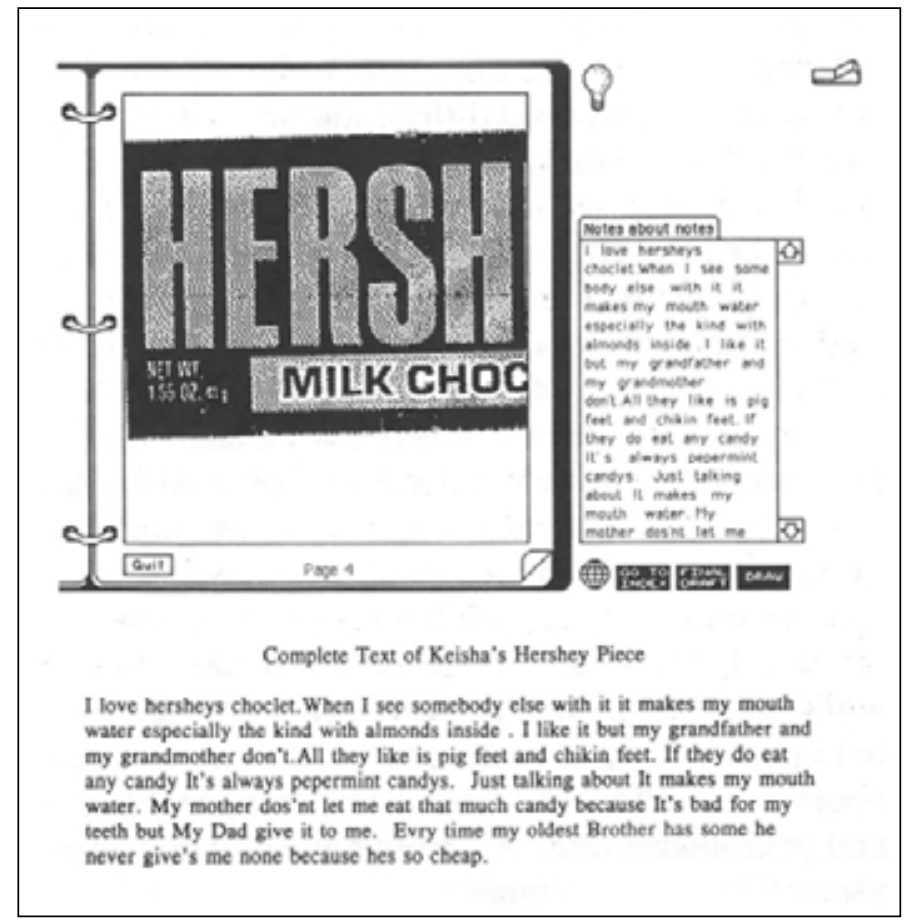

Fig. 2: Keisha's story

Analyses of the students' composing processes and texts revealed flexible and productive uses of the diverse digital tools. As shown in Figure 2, Keisha used the image of a candy wrapper (entered into the database by someone else) as a springboard for a story not about candy alone but about her relationship with a beloved grandfather. The visual mode, thus, served as a prompt, in large part via what appears to be a sensual connection from one kind of candy to another and beyond, eliciting another kind of affective memory. Keisha's teacher and analyses from the study indicated that this narrative was the most fluent and coherent that this student had written all year. Another student used multi-modality in a different 
way, shifting in real time from a digitized image of a music idol, drawing tools to add features to the musician's album cover, digitized snippets of a song by the artist, and the young author's writing about listening to this music in his neighborhood. This educationally directed activity — writing a book about contemporary culture-with a range of symbolic modes in the digital world is an example of an integration of tools and purposes to expand students' local horizons.

Another major digital feature is the storage and search capacity of the digital world.

\section{Vast Sources of Knowledge and Experience}

Given the constant and increasing amount of information in the digital world, students need to develop skills for accessing it. Creating databases, as Keisha and her classmates did, can provide a foundation for defining digital databases, their design, issues related to their development, and processes for accessing information-archived and live. Searching wikis and doing collaborative projects to stretch students' spontaneous realms of interest can guide their knowledge that those resources exist and can serve purposes beyond staying in touch with friends. Using digital tools for student research projects may not seem as appealing as using social media, but engaging students' activities and imaginations has scholarly and ethical value, as well as educational value. Because using digital tools to expand beyond one's personal concerns and milieu is not so easy, defining search purposes and processes requires educational guidance. Also benefitting from discussion in educational contexts is the fact that while the Internet provides recourses beyond a close circle of friends and family, there are dangers and supports. Like parents, teachers, librarians, and other professionals in educational contexts should be resources students can turn to about such issues.

Especially limited has been research on children's digital searching strategies. Search strategies require learning goals, not the closed-ended kinds for specific answers, but expansive goals that offer ongoing guidance and inspiration. With the general goal I have proposed of interacting with diverse others about their plights, a first step must be to have a framework, such as a project to learn about how those on the other side of a conflict divide feel about it. The next goal is for students to work interactively in their local contexts to discuss ideas for questions about what they would like to find out, need to find out, cautions, and ultimate uses of the information they gather. Available research indicates that this process has been, for the most part, the province of media specialists and librarians (Gray, 1994; Mendrinos, 1995). The 
spate of research interest in this topic in the 1990s seems to have subsided, perhaps because search skills are taken for granted, given the apparent ubiquity of the digital world or the relative transparency of the student research process. Nevertheless, that many young people spend time in the digital world does not mean they are using search processes to expand their knowledge.

Augmenting databases like books, journals, newspapers, YouTube resources, and wikis, students can interact with others who have knowledge, experience, and insights likely to be comparable to their own. Compelling social purposes can, with some guidance, be extended to serve scholarly and community development purposes. Some young people may, of course, do so spontaneously, but even they could benefit from ideas and structure for research projects. Young people across the region where we did the online peer survey-interview activity knew, for example, of certain events that led to the wars, albeit from the perspectives of their own country and certain impressions that others had about their country. Information in the media, from migrants across the region provided such insights, but direct and diverse interactions were needed to break the local rigid scripts on any single side of the war. Given the opportunity to inquire about the lives of youth in other areas, about whom they had some knowledge, some assumptions, and, no doubt, some prejudices, sparked participants' curiosity and empathy. Inquiries of peers living in different political positions brought contradictory ideas together, for example whether adolescents across sites of political conflict experience ongoing discrimination because of ethnicities that, in part, fueled the war. Asking rather than only answering questions shifted agent-audience relationships, thus prompting some participants to realize they had actually never considered their peers' plights. Asking questions is, moreover, foundational to navigating the enormous digital world. As question askers, young people can expand their receptivity to diverse ways of knowing and knowledge.

Because of the vast sources online, educators can help students figure out the best digital tools for increasing knowledge and social relations-tools for connecting with others and one's self, critically and creatively. Using digital environments and tools in these ways is not only instrumental for creating knowledge products, but also useful for purposes of human development. Research and practice must continue to explore how students use the digital world and what they gain from using specific features, such as interactivity, multi-modality, and information. 


\section{Relational Projects in Digital Worlds}

Still needed are educational designs to guide students' and society's prosocial development. Educational projects in digital worlds can implement collective purposes among face-to-face and distant groups building from local and global issues, like immigration, displacement, unemployment, social media miscommunications, and other problems worthy of the energy of students across upper elementary through high school. This focus on using digital affordances along with others in relation to cultural realities like the roles of diverse institutional actors is consistent with other socio-cultural approaches (Cole, 2010; Gee, 2013; Kress, 2003; Hull \& Nelson, 2005). A brief review of theory about the role of education in the digital world is a reminder of the need for a renewed educational agenda.

Epistemological assumptions guiding research and practice with learning technologies have shifted from behaviorist to constructivist to socio-cultural. Explanations of relationships among the computer, teaching, and learning have, for the most part, changed since the 1980s when microcomputers entered public $\mathrm{K}$ through 12 schooling. An early focus was on computers as teaching devices, with the attendant excitement, doubts, and fears. Educators then applied constructivist theory to explain that children would, at different ages, interact with the capacities of technological tools based on their own developing capacities. This shift was represented by an emphasis on computer-aided instruction for teaching specific skills (Skinner, 1961; Taylor, 1980) to uses of computers to facilitate early writing development (Daiute, 1985), geometry with child-friendly programming languages (Papert, 1993), problem finding and problem solving with diverse symbolic media (Bamberger \& Schon, 1991), and visually rich environments integrated with symbolic media for simulations (Cognition and Technology Group, 1992). Contemporary theorists of learning and development have explained that digital technologies serve as mediators of human activity-useful tools for figuring out what is going on in the world and how one fits.

Scholars are increasingly interpreting digital systems as they do other uniquely human symbol systems like speech (Vygotsky, 1978). Words are cultural technologies (Ong, 1982), and novels are like utterances offered in chains of communication across time and place (Bakhtin, 1986). From the perspective of socio-cultural and activity theories, educational researchers have emphasized the use of technologies to mediate interactions (Cole, 1998; Daiute, 1985; 1993; Hull \& Nelson, 2005; Stone \& Guitierrez, 2007). The interactive qualities linking diverse audiences for real purposes include, for example, university students participating in community development (Cole, 2010), children of formerly warring groups communicating (Daiute, 2010), 
multimedia student writers using diverse symbolic modes (Hull \& Nelson, 2005), and children expanding their perspectives through on-screen role models (Richert, Robb, \& Smith, 2011). Consistent approaches for teaching and learning in the digital world have focused on the digital world as a "scaffold," in one strand of research explaining that "the growing prevalence of screen media in young children's lives suggests technology itself may function as a more advanced partner scaffolding children's developing abilities and facilitating learning" (Richert et al., 2011, p. 82), relating to and learning from characters on the screen (Calvert, Strong, Jacobs, \& Conger, 2007; Hoffner, 2008).

In spite of such theoretical advances, few consistent lines of inquiry have survived, in part because research tends to be defined in terms of specific hardware and software rather than features (like those discussed above). Moreover, recently published research indicates that the pendulum sometimes swings back to suggest a one-way process from technology to student, as suggested by numerous research articles reporting the "impact," "effects," or "learning from" technology, rather than explaining the mediational uses of technologies in the midst of a range of collaborative purposeful activities. What insights are especially relevant for educators wanting to employ this theory of technology use to mediate global contexts for human developmental purposes?

\section{Interacting With Diverse Others}

The digital world and digital tools for communication, knowledge acquisition, and goal-making have become increasingly easy to use, flexible, ubiquitous, and immediate, although not in all places. What has also changed dramatically is the world in which the digital world is embedded. These capacities stand, for the most part, in parallel to contemporary needs of human civilization. As the digital world has expanded across the 20th to the 21st century, scholarly and popular writing about human social interaction has also increased dramatically. One reason for the increased attention to interactive abilities and purposes-in the digital world and around it-is that environments where children are growing up are changing rapidly. We should, thus, be exploring developmental concepts that 21st century children are using as they interact in unstable contexts. The more young people encounter others with diverse experiences, ways of knowing, and interacting in the world, the more they have to develop skills for negotiating differences-not as neutral processes but as fraught with issues of inequality, prejudice, and conflict. This argument for "pro-social" (Higgins-D'Alessandro, 2012) and "non-cognitive" capacities is increasing in developmental literature (Boyden \& Dercon, 2012). Cognition-language and 
thought-are inextricably integrated with social and affective processes. While any teaching and learning agenda cannot address all needs for human development, educators can better define the teaching/learning process as interacting in the complex social, cultural, and material world, using digital tools to mediate knowledge and experience rather than merely transmitting them. An important question for educators to consider in this process is whether and how their students use the digital world to steer increasingly toward people who think and look like them or to do the more difficult task of considering difference.

A socio-cognitive skill that seems especially relevant to contemporary circumstances is something like perspective-taking. Interestingly, scholarly writing about perspective-taking has risen increasingly over the 2000s, after a drop in citations from the 1970s through the 1980s and 1990s. In addition to "perspectivetaking," concepts like "diversity management" and "social inclusion" have increased, adding cross-cultural and institutional dimensions to mutual understanding. Consistent with those expansions is the concept "relational complexity." Beyond interpersonal perspective-taking, relational complexity involves multi-dimensional interactions across individual (child), group (ethnic history and affiliation), generation (as historical circumstances change) and institution (such as school) positions by those in different societal roles, such as student, teacher, administrator. These roles embed diverse resources, influences (power), and goals in the communication process and resulting meanings. Relational complexity, thus, accounts for structural relations, reflecting the increasing need globally for individuals across the life span to relate to others who live, believe, think, and know differently because of language, culture, religion, and politics.

Children as young as 3rd grade in U.S. public schools and young adults in politically and economically unstable contexts in countries elsewhere use diverse genres for relational complexity-connecting in intra-personally sensitive ways to diverse knowledge in diverse situations and with diverse audiences. Paying attention to relational complexity as a process and goal is likely to shift educators' perspectives, as well. For example, we often value autobiographical genres as means of bringing students' personal perspectives into the classroom; nevertheless, there is evidence that autobiographical genres are most useful for conforming to expected mores, while fictional narratives are useful for questioning expectations or expressing less-than-ideal mores (Daiute, 2010). For example, Moira in Croatia used autobiographical writing about a conflict she observed to conform to expected values of moving beyond the conflict by means of compromise for a greater good: 
Misunderstandings always begin when people love each other. If people didn't care about each other, all the problems would be forgotten without any effort spent in trying to solve them. People would simply go their way. My aunt has a boyfriend who is a biker. At the parties he goes to, men always have to be the first in everything and have the best bike and the prettiest woman sitting in their lap. The conflict between my aunt and his boyfriend began because of a striper who was seeing my aunt's boyfriend. They usually tried to solve their conflicts with loud and long lasting conversations. ... They annulled their marriage but their relationship had many revivals. In the end they were happy because they insisted on preserving their relationship. In their age it isn't easy to find someone who suits you completely, so they decided to accept their flaws and find a common language. Now the story has a happy ending because my aunt is pregnant. (Daiute, database)

Moira organized that conflict as a "misunderstanding" among people who "love each other" and, ultimately, "preserving their relationship."

In contrast, when writing a fictional account positioning her as outside the narrative actions, this same author expressed values related to her country's justification for war and their righteous victory. An allegory with the "Greens" and "Blues" as antagonists (thinly veiled as Serbs and Croats), the following narrative elicited as a fictional story expresses a political ideology that would be less acceptable, especially among many future-oriented youth in present-day Croatia.

The Greens and The Blues created this center in order for it to be the main place for social development of our town. The Greens were ready to do everything. They didn't mind the fact that the Blues participated in some other community centers in other towns. The Blues were loyal to the Greens as much as they were to the other partners. They had enough time and will to be active in many places. The news they told the Greens destroyed everything. With time, the Greens showed they weren't open for cooperation with others. They wanted their capital and their success only for themselves. They didn't realize that it was possible to be even more successful through cooperation with others. The Blues weren't able to explain them how they weren't the traitors and that they didn't operate behind the Greens' backs. In the end, the Blues, cooperating with others became even more successful, while the Greens failed completely. The projects the Blues and others were writing helped the development of many towns. Few years later, they called the Greens to join them. (Daiute, 2010, p. 114)

The ultimate contribution of the relational complexity concept to be explored further is the use of cultural tools in this technological age-to mediate a variety of one's relations from peers to powers, parental and political. Education can 
serve to direct and connect people as they search the massive content and Babel that's on the Internet. Although interaction abounds, it is likely that engaging in challenging communications may require guidance, not to challenge for its own sake but to provoke synergistic thinking, among, for example, people on opposite sides of wars; participants in different educational contexts (university, school, and community institutions) (Cole $\&$ the Distributed Literacy Consortium, 2006), users of MUDDS (Turkle, 1995), and pro-social gamers (Gee, 2007).

Relational complexity is increasingly possible to provoke and support with educational designs in digital worlds, where multiple diverse audiences are available. Interaction with those diverse others to find and/or pursue common purpose can expose students to diverse audiences, responses to their writing, and responses to others' writing. The plethora of other interlocutors in digital worlds also provides opportunities to learn about responses from those who are similar and different in a variety of ways - such as an age-mate growing up in a very different culture, a person of a different age growing up in the same religion, an institutional representative (such as a governmental head) in a very different role from the student. Crafting these interactional experiences is an educator's job, in part because the principled diverse interactions are not likely to occur spontaneously.

\section{Using Hyper-imaginaries}

Considered together, the features of the digital world allow for hyperimaginaries. Imagination employing cultural tools remains the mediator of life, while blogs, wikis, social media, writing, radio, and other technological tools fuel imagination. In research to understand how poor migrants made decisions to embark on perilous journeys, such as across oceans in small ill-equipped boats, in spite of media evidence that odds are greatly stacked against their successful arrival, one scholar wrote the following:

Our social imaginary oscillates between presentia and potentia thereby prolonging being into possible becoming, and when looking at the way people envision themselves as agents and social categories - as groups of people within and among others in time and space - this imagined community often gains a holistic character, simply because people see themselves as wholes and parts of wholes in relation to their historical becoming. (Vigh, 2009, p. 99) 
Complex uses of symbolic thought to act in the world and on one's self is a uniquely human capacity. From the beginning of life, babies put these capacities to work, understanding, for example, that a parent's pointing finger means "Look there" and that repeated sounds like "Mama" refer to a specific person, and so on. As educators teaching with digital tools know, children and youth participate with technologies in their realm spontaneously. The work for us is to understand the important features and activities in the digital world that young people do not use spontaneously, do not use for developmental ends, or use for counter-developmental ends. Recognizing those uses, we can create projects that would otherwise probably not occur. Expanding the imaginary-knowledge, thought, conceptual strategies, and communicative genres - is one of the major goals of education. Teaching the tools of science (physics), math (geometry), literacy, literature, analysis of civilization, prior uses of those tools, and the attendant purposes of those tools, is for example, much of what we do in education. Consistent with that view, supporting the best uses of hyper-imaginaries could be a major focus of teaching and learning in the digital world.

Reading books about the lives of children in distant countries is essential; communicating with those children via the Internet advances learning about other children to experiencing their thinking verbally or visually. Guided projects to address cultural and other differences in rational ways are currently possible in the digital world, albeit still for the most part a frontier in practice. The digital youth survey is an example with the multiple means of interaction, multiple-symbol systems, and engagement of knowledge bases in a way that brings age-mates who experienced a war on the opposite side of reason into the room as potential audiences to consider. Inevitably, when responses are entered, which could be during a class session, by the next meeting of a class, or within a week, there will be differences that are offputting, foreign, or even abhorrent. Here again is where the organizational structure of teaching and learning is crucial for engaging students with diversity, rather than allowing them to turn away or to retreat to only familiar ways of knowing. How to understand diverse perspectives, analyze and learn from them, or agree to disagree is still on the horizon of educational practice and research with hyper-imaginaries. The digital world is not absolutely necessary for such practice, but with enlightened educational projects building on interactivity, multi-modality, archived and live information sources, digital tools can greatly enhance imagination. While many make the distinction between on-line and off-line life as a distinction between not real and real, imagination is the basis of the real. The most brilliant scholars across time have explained that it is social culture that creates mind, mind that creates activity, and this meaningful activity that organizes everyday life. 


\section{Learning for Self- and Societal-determination}

One expectation of the digital world is that it would increase democratic processes. Although recent socio-political innovations like the Occupy Movement and the Arab Spring, which involved masses of people, many of them young students, expressing their opinions, intentions for political change, and ideas for how that would occur, the Internet has not proved the magical tool for democratic change (Sitrin \& Azzinelli, 2012). Blocks to such change have to do with the concentrations of power and inequality in the material worlds where virtual worlds reside. That said, the interactive, multi-modal, and storage qualities of the digital world can be mined for authoritative uses by individuals and groups with developmental goals. The intentions and plans for such educational initiatives are in need of guidance-the kind of guidance possible in educational contexts.

Having designed and implemented the "Wizard" project to involve crossgenerational communication for community problem solving, Cole (2010) summarized

...it is important to recognize that we provide the kinds of education our social ecologies permit and promote, failures and all. It is changes in the modes of human life, including the role of education in promoting human adaptation, that will ultimately shape the forms that educational activity takes... (p. 804)

Another scholar explained how, with some structure in place, the developmental process occurs.

[An] intergenerational interaction between a child and undergraduate as they engage in activities that represent two varieties of the imaginary situation proposed by Vygotsky: Playing a game and orienting to the 'mythical figurehead,' a fantasy figure common to all Fifth Dimension sites. ... As the interaction unfolds, child and undergraduate are seen to engage creatively with both game and [face-to-face] site rules as they create a collaborative and increasingly complex representation of the mythical figurehead. The participants' engagement with rules ... provides the child with multiple opportunities, together with those prompted by the site artifacts, to affect and negotiate the Fifth Dimension experience. (Poole, 2011, p. 216)

In conclusion, engaging students in important purposeful interactions with diverse others is a way to expand the horizons of education by expanding interpersonal and inter-cultural understanding. While digital worlds continue to transform 
in many ways, educational projects must mobilize interactivity, multi-modality, and vast databases of information, which endure along with welcomed changes in portability, flexibility and, for some, accessibility. These digital capacities serve teaching and learning to mediate students' symbolic control, knowledge, and participation in critical and creative thinking about and with others and one's self. Considered together these capacities are most useful for provoking students' interactions with diverse others to expand their horizons, not only to acquire information about other places and other peoples, but also with the affective and intentional goals to understand the world around them and how they fit. Given the ubiquity of digital tools and the vast range of all kinds of information and chatter therein, it takes education to guide and nurture that process.

\section{Note}

1. The efficiency of different tools-immediacy and speed of interaction-makes a difference but whether and how remains an empirical question.

\section{References}

Bakhtin, M. M. (1986). The problem of speech genres. In C. Emerson \& M. Holquist (Eds.), Speech genres and other late essays (pp. 60-102). Austin: University of Texas Press.

Bamberger, J., \& Schon, D. (1991). Learning as reflective conversation with materials. In Research and reflexivity (ed. F. Steier) (pp. 186-209). London: SAGE Publications.

Boyden, J., \& Dercon, S. (2012). Child development and economic development: Lessons and future challenges. Oxford, UK: Young Lives: Oxford University.

Calvert, S. L., Strong, B. L., Jacobs, E. L., \& Conger, E. E. (2007). Interaction and participation for young Hispanic and Caucasian girls' and boys' learning of media content. Media Psychology, 9, 431-445.
Cognition and Technology Group at Vanderbilt. (1992). The Jasper experiment: An exploration of issues in learning and instructional design. Educational Technology Research and Design, 40(1), 65-80.

Cole, M. (1998). Cultural psychology: A once and future discipline. Cambridge, MA: Harvard University Press.

Cole, M. (2010). Education as an intergenerational process of human learning, teaching, and development. American Psychologist, 796-807.

Cole, M., \& the Distributed Literacy Consortium. (Eds.). (2006). The Fifth Dimension. An after-school program built on diversity. New York: Russell Sage Foundation.

Daiute, C. (1985). Writing and computers. Addison-Wesley Publishers. 
Daiute, C. (April, 1992). Multimedia composing: Extending the resources of kindergarten to writers across the grades. Language Arts, 69, 250-260.

Daiute, C. (1993). The development of literacy through social interaction. San Francisco: Jossey Bass.

Daiute, C. (2010). Human development and political violence. New York: Cambridge University Press.

Daiute, C., \& Morse, F. (1993). Access to knowledge and expression: Multimedia writing tools for children with diverse needs and strengths. Journal of Special Education Technology, 12(3), 1-35.

Gee, J. P. (2007). Good video games - good learning: Collected essays on video games, learning, and literacy. New York: Peter Lang.

Gee, J. P. (2013). The anti-education era: Creating smarter students through digital learning. New York: Macmillan Palgrave.

Gray, R. A. (1994). The School Media Specialist: Teaching in the Information Age. TechTrends, 39(6), 45-46.

Higgins-D'Alessandro, A. (2012). In P.M. Brown, M.W. Corrigan, A. Higgins- D'Alessandro (Eds.) Handbook of Prosocial Education. (pp. 3-38). Plymouth, UK: Rowman \& Littlefield Publishers, Inc.

Hoffner, C. (2008). Parasocial and online social relationships. In S. L. Calvert \& B. Wilson (Eds.), Handbook on children, media, and development (pp. 309-333). Boston: Blackwell.

Hull, G.A., \& Nelson, M.E. (2005). Locating the semiotic power of multimodality. Written Communication, 22, 224-262.

Kress, G. (2003). Literacy in the new media age. London: Routledge.

Lucić, L. (2012). How do youth make sense of interpersonal interactions and resolve conflicts with diverse groups? (Doctoral dissertation). New York: Graduate Center, City University of New York.
Mendrinos, R. (1995). Building information literacy using high technology: A guide for schools and libraries. Englewood, CO: Libraries Unlimited, Inc.

Ong, W. J. (1982). Orality and literacy: The technologizing of the word. New York: Methuen.

Papert, S.A. (1993). Mindstorms: Children, computers, and powerful ideas. New York: Basic Books.

Poole, D. (2011). "Mao Might Cheat": The Interactional Construction of the Imaginary Situation in a Fifth Dimension AfterSchool Setting. Mind, Culture, and Activity, 18: 216-236.

Richert, R.A., Robb, M.B., \& Smith, E. I. (2011). Media as social partners: The social nature of young children's learning from screen media. Child Development, 82(1), 82-95.

Sitrin, M., \& Azzelini, D. (2012). Occupying language: The sacred rendezvous with history and the present. Brooklyn, NY: Zuccotti Park Press.

Skinner, B.F. (1961). Why we need teaching machines. Harvard Educational Review, 31(4), 376-398.

Stone, L. D., \& Guitierrez, K.D. (2007). Problem articulation and the processes of assistance: An activity theoretic view of mediation in game play. International Journal of Educational Research, 46, 43-56.

Taylor, R. (1980). The computer in the school: Tutor, tool, tutee. New York: Teachers College Press.

Turkle, S. (1995) Life on the screen: identity in the age of the Internet. London: Phoenix.

Vigh, H. (2009) Wayward migration: On imagined futures and technological divides. Ethnos, 74(1), 91-109.

Vygotsky, L. S. (1978). Mind in society: The development of higher psychological processes. Cambridge, MA: Harvard University Press. 


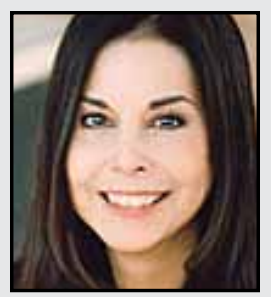

Colette Daiute is Professor of Psychology at the Graduate Center, City University of New York. Dr. Daiute does research on child and youth development in extremely challenging and changing environments. Her recent book publications include Human Development and Political Violence (Cambridge University Press, 2010) and Narrative Inquiry: A Dynamic Approach (Sage Publications, 2013). Recent journal articles include "Human development in global systems," Global Studies Journal, 2012 and " 'Trouble' in, around, and between narratives," Narrative Inquiry, 2011. She teaches graduate courses on "Human Development and Globalization," "Narrative Inquiry," and "Developmental Theory and Interventions" as well as related professional development workshops for experienced scholars.

\section{LINK TO:}

http://www.colettedaiute.org 